\title{
A preliminary result of microtremor study to identify the subsurface condition in the Aceh Tenggara region
}

\author{
Andrean V. H. Simanjuntak ${ }^{1,3}$, Umar Muksin ${ }^{2,3 *}$ \\ ${ }^{1}$ Badan Meteorologi Klimatologi dan Geofisika (BMKG), 22123Aceh Besar, Aceh, Indonesia \\ ${ }^{2}$ Department of Physics of Universitas Syiah Kuala (USK), 22122 Banda Aceh, Aceh, Indonesia \\ ${ }^{3}$ Tsunami and Disaster Mitigation Research Center (TDMRC), Universitas Syiah Kuala (USK), 23111 Banda Aceh, Aceh, Indonesia
}

\begin{abstract}
The Aceh Tenggara region is located in an tectonically active region and it can be categorized as the prone-area. Historically, there were many major earthquakes occured the active fault called the Tripa segment that has generated massive damages and losses. The study of the seismic vulnerability around the highly populated city in the Aceh Tenggara region, Kutacane City, as the center of economy and office activities must be conducted to prepare the suitable earthquake mitigation program. The microtremor have been recorded at 25 sites with one km grid interval between all points. The record lengths have 30 minutes duration at each site, and they were measured with the Taurus Seismometer in miniseed format. The data were analyzed by using the HVSRpy in order to obtain the Horizontal to Vertical Spectral Ratio for each site by means of the geometric-mean and the multiple azimuths methods. Both methods provided a similar result at both focuses with dominant frequency of $0.8 \mathrm{~Hz}$ at the AT01 site and $4.8 \mathrm{~Hz}$ at the AT14 location. The preliminary result shows that the higher dominant frequency were recorded along the southern part of the Kutacane city which is associated with the Alas formation.
\end{abstract}

\section{Introduction}

The Aceh Tenggara region is surrounded by active faults and categorized as the seismic prone area as shown in Figure 1. The Tripa fault is the longest segment along the Sumatran fault in Aceh that has generated earthquakes with a magnitude of M 6.8 in 1990 and with M 7.2 in $1996[1,2]$. Another major earthquake also occurred in the northern part of the Tripa fault on July 2, 2013 with M 6.2 which is strongly felt by the local people in the Aceh Tenggara region [2,3,4].

All major earthquakes generated the intensity of between 4-6 MMI (Modified Mercalli Intensity). The intensity was influenced by the subsurface condition from the basin structure in the Aceh Tenggara region [5, $6,7,8]$. The seismic surface waveform will be trapped in long period and amplified up to 2.0 times greater than the normal recording in the basin area $[9,10,11]$. On other hand, geomorphological studies show that the highest risk level occurred in the basin with alluvial sediment $[12,3]$.

Furthermore, Irwandi et al. [12] updated the seismic hazard for the Southeast Aceh region to the probability figure exceeding $2 \%$ and $10 \%$ for 50 years to produce the bedrock PGA (Peak Ground Acceleration) map. The basin structure may amplify the PGA due to the young alluvium (Qh) structure. The amplification results clearly show that the PGA can reach $0.9 \mathrm{~g}$ and $1.5 \mathrm{~g}$ for $10 \%$ and $2 \%$ which are likely to be exceeded for 50 years with ratio reaching 1.6 times in the more densely populated areas in the Kutacane basin.

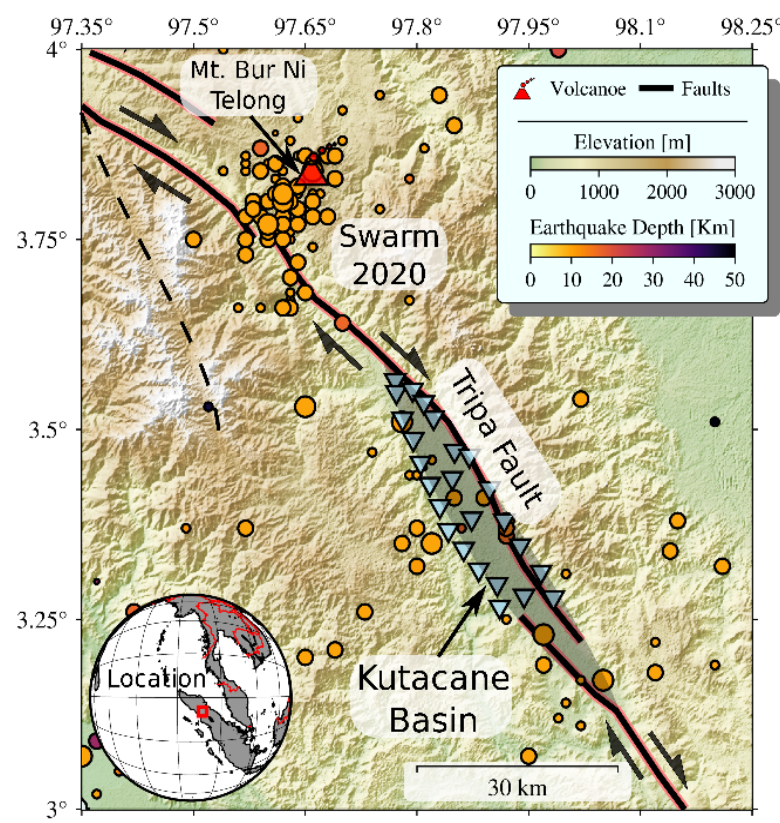

Fig. 1. The tectonic system in the study area with an active fault namely Tripa fault. There were swarm activities in 2020 in the northern part of study area.

Here, we conducted a microtremor study to figure out the subsurface condition and its impact represented by the vulnerability level. Microtremor research has been widely studied through the HVSR method was used to investigate the site characteristics for earthquake mitigation for example, the soil condition after the earthquake [5], the site and soil amplification effect

\footnotetext{
* Corresponding author: muksin.umar@unsyiah.ac.id
} 
$[11]$, microzonation $[9,10]$ and the shallow sedimentary properties [12].

Theoretically, microtremor utilizes the ratio of horizontal to vertical components of ambient noise (microtremor) to study the site condition. The site condition was represented by the dominant frequency (f0), the amplification factor (A), and the seismic vulnerability index $(\mathrm{Kg})$ of recording microtremors.

In this paper, we applied the HVSR method for two points as the preliminary study. The two points show the different parameters which were influenced by lateral heterogeneity. The future study is to continue the data analysis for more points that are believed to be essential in term of learning the seismic vulnerability for disaster mitigation program in the Aceh Tenggara region.

\section{Data and method}

\subsection{Data observation and location}

Microtremor were recorded in the Kutacane city which is part of the Aceh Tenggara region. The Kutacane city was chosen mainly because the city located along the active fault, stands on the basin structure, and densely populated. The microtremor records with a total of 25 locations, as shown in Figure 3, were measured by using a short period Taurus seismometer with a sampling rate of $100 \mathrm{sps}$ (sample per second) and recording time between 30 - 45 minutes for all observation points.

The local geology of study area with the regional scale of 1:150.000 is shown in Figure 2. The Aceh Tenggara region is part of Medan sheet on the right area while left area is included in the Tapaktuan sheet. The rock structure of the study area is composed by Alas (Ppa) and Bohorok formation (Pub) that is formed since Paleozoic age by high pressure from the subduction activity $[10,11]$.

The Alas Formation (Ppa) located on the southern part is more compact than the northern part due to the high topographical contour. The Alas formation consists of limestone rock (Murl) while the younger formation of Alluvium (Qh) filled with the clastic sediment that can be found on the northern part. This formation comprises of the fractured sedimentary rock of pull-apart basin caused by tectonic activities along the Sumatran fault [10]. The alluvium sediment known as the Kutacane graben has been formed since the Cenozoic to the Neogene period. The graben is categorized as the product of an active fault namely Tripa fault. The Tripa fault moves in the right-lateral direction with slip rate of $\sim 20 \mathrm{~cm} / \mathrm{yr}$.

The pull-apart basin in the Aceh Tenggara proves to be a very interesting structural surface with a swarm activity in the northern part (See Figure 1), the dextral earthquake in the central part and located close to the Mount Sinabung in the southern part. As a densely populated area, the Kutacane city region can be categorized as a disaster prone-area that needs a comprehensive study to highlight the potential hazard especially caused by the earthquake.

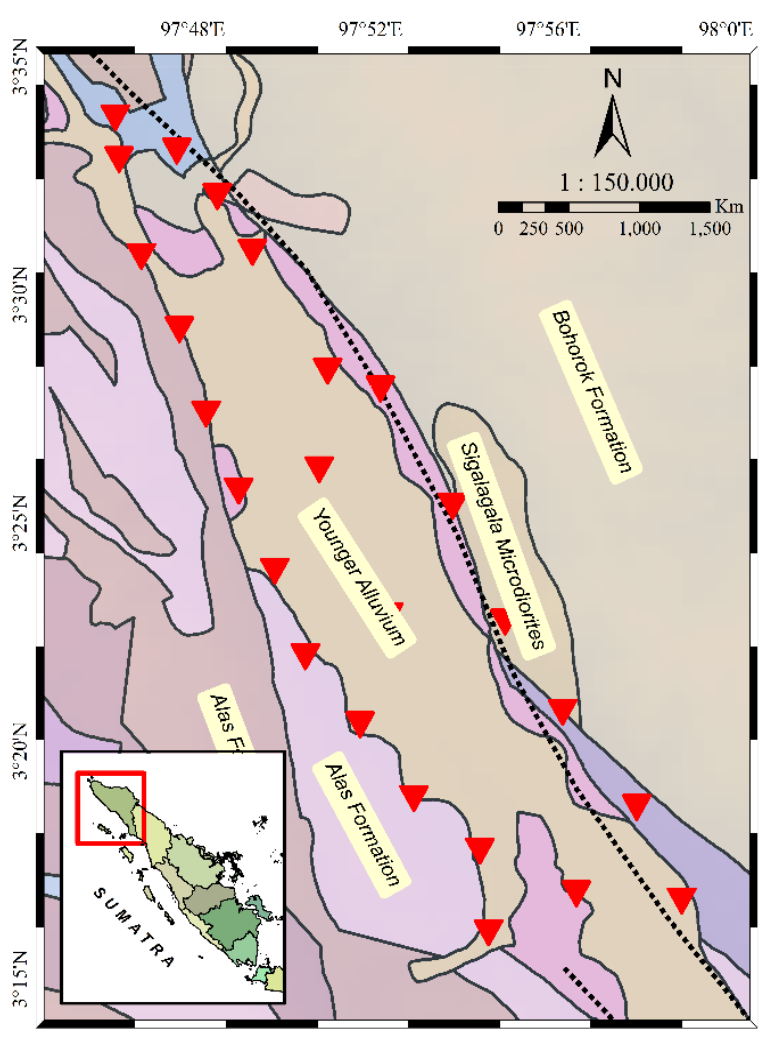

Fig. 2. Map of study area and local geology in the Southeast Aceh. Total of observation points were 25 sites that covered the basin structure. The basin structure in the Southeast Aceh consists of young alluvium sediment $(\mathrm{Qh})$.

The earthquake in the Aceh Tenggara region is dominantly triggered by the subduction from IndoAustralia-and-Eurasia convergence. The shaking from the earthquake is likely amplified when it travels through the graben and the basin structure in Kutacane. A routine observation from the Meteorological, Climatological, and Geophysical Agency [Badan Meteorology Klimatologi dan Geofisika (BMKG)] shows an average intensity of moderate earthquake in the range of 4-7 MMI $[12,13]$. For that reason, we try to conduct a microtremor study to highlight the frequency and the amplification characteristics in the Southeast Aceh by using the geometric-mean and the multiple azimuth methods. This research aims to provide a preliminary of microtremor parameters that can be used to study the earthquake mitigation plan and preparation in the Southeast Aceh region

\subsection{Horizontal Vertical Spectral Ratio (HVSR)}

The method of $\mathrm{H} / \mathrm{V}$ ratio compares the Fourier spectrum of horizontal to vertical component which represented the amplification of a site Nakamura [14]. By using similar approach, Stanko et al. [15] determined the H/V values based on the maximum spectrum of $\mathrm{H} / \mathrm{V}$ value of 1 was found on the site in hard rock structure.

On the other hand, the amplification parameter in the stations that stand on the soft rock structure has the maximum greater than 1. From the amplification, a further analysis can be formulated as a transfer function of $\mathrm{H} / \mathrm{V}$ spectral ratio [16]. Then, the time domain must be changed into the frequency domain with the Fast 
Fourier Transform (FFT) to find out the specific frequency for upper and lower frequency corner. The Bandpass Butterworth filter with an appropriate corner frequency can be used automatically to get a typical range micro frequency [17].

Here, two horizontal components are combined with the vertical component with the geometric-mean and the multiple azimuths method. The processing procedure was following the recommendations of [18, 9] namely, that if a single HVSR trend is determined, then the lognormal median curve can be calculated using the geometric-mean. Furthermore, a statistical modelling of fo can be calculated and the multipleazimuth can be used [20, 21]. In this paper we used a python program namely hvsrpy, which is an opensource package for HVSR analysis [20,21]. The hvsrpy was built to highlight the new HVSR processing techniques that is proposed by $[18,19,20,22]$.

\section{Result and discussion}

For the HVSR analysis, we employ the settings of the time tab window selection process which includes the sub-tabs of window length, cosine taper width, and timedomain filter as in $[18,19]$.
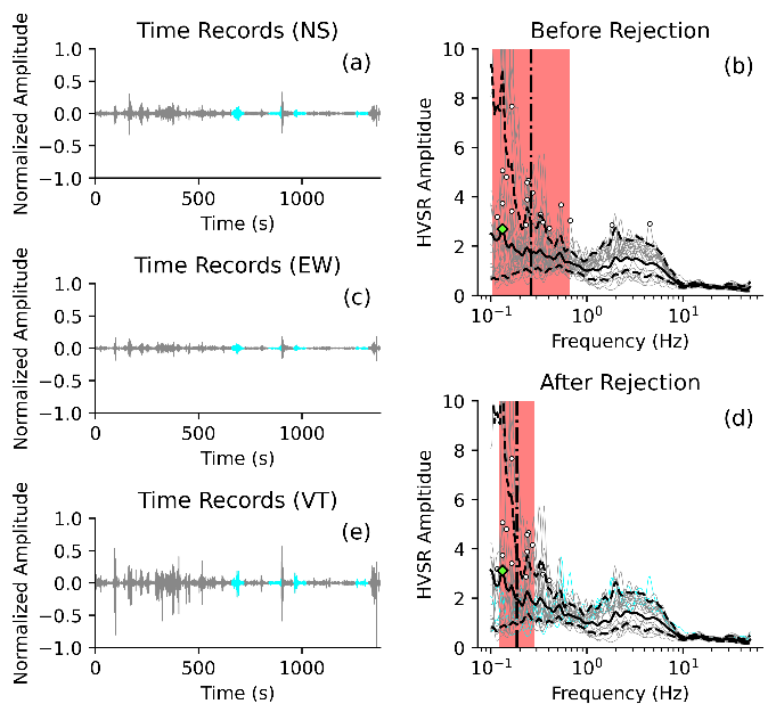

Accepted $\circ f_{0, i}-L M_{\text {curve }}$ Rejected $\diamond f_{0, m c}--\quad L M_{\text {curve }} \pm 1$ STD

Fig. 3. Example results from the hvsr recording at point one (AT01) which had been calculated with the geometric-mean method. The seismic waveform is illustrated in the three geographical components (a) in the north-south (NS) component, (c) east-west (EW) component, and (e) vertical (VT) component. with rejected and accepted windows in the Frequency-domain.

In other hand, SESAME (2004) noted that the HVSR processing will be better with the time windows in a minimum ten times of $1 / \mathrm{f} 0$. In this study, transient effects were determined by using anti-triggering correlation of Short-Term Average (STA) and the LongTerm Average (LTA) at $0-30$ seconds with a window of 60 seconds and a cosine taper of $\pm 10 \%$ as shown in Figure 3, while the azimuth angle in Figure 4.

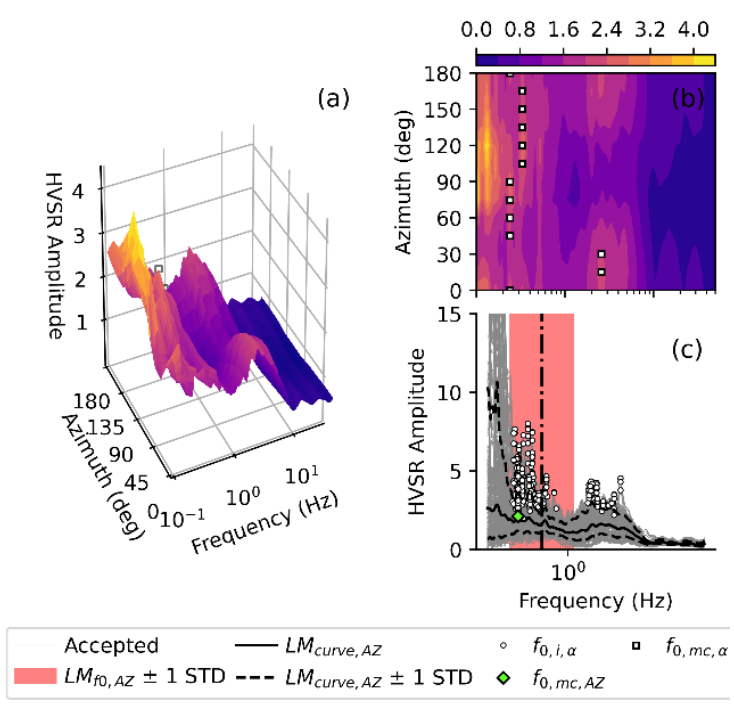

Fig. 4. Example results from the seismic waveform at point one (AT01). (a) The median curve for all azimuth angles in the frequency-azimuth-amplitude space. (b) The spectrogram between the lognormal median trend and all azimuth angles. (c) The HVSR trend from all azimuth angle.

We also analysed another point in the left part of the study area at AT14 as shown in figure 5 and 6 for the comparison values.

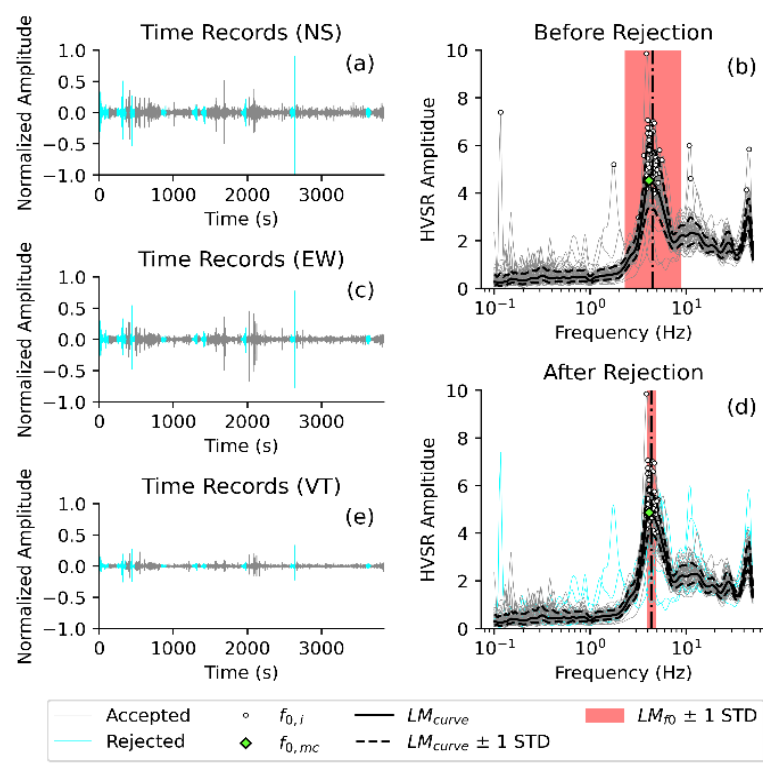

Fig. 5. Example results from the seismic waveform at another point (AT14). The seismic waveform is presented in the three geographical components (a) north-south, (c) east-west, and (e) vertical with the windows rejected in the frequency domain.

The Konno-Ohmachi (1998) smoothing coefficient of 40 is applied to smooth the seismic waveform data at a frequency range of $0.1-50 \mathrm{~Hz}$. Then, the geometricmean processing is used for the $\mathrm{H} / \mathrm{V}$ results in the lognormal frequency-amplitude (see Figure 3). Point one (AT01) is assumed with soft alluvial sediment formation that has frequency of $\sim 0.8 \mathrm{~Hz}$. Meanwhile, another method that used in this paper is the multiple azimuths (Figure 4). We also applied the KonnoOhmachi smoothing coefficient of 40 at the frequency 
range of $0.1-50 \mathrm{~Hz}$. The similar technique is used for $\mathrm{H} / \mathrm{V}$ values in the lognormal frequency-amplitude distribution as shown in Figure 5 and 6.

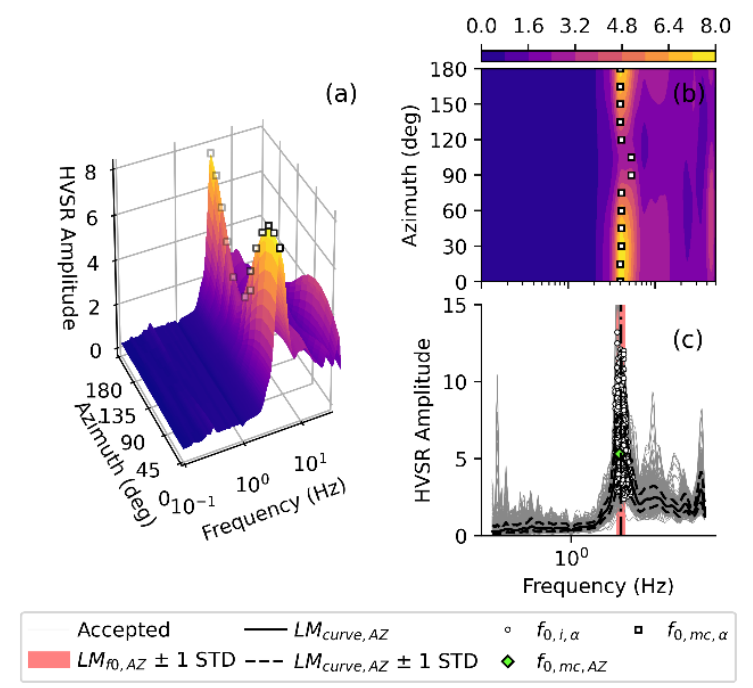

Fig. 6. The results example from the seismic waveform at another point (AT14. (a) The median trend for all azimuth angle in the frequency-azimuth-amplitude domain. (b) The spectrogram between the lognormal median curve and all azimuth angle. (c) The HVSR curves from all azimuth angle.

Point AT14 shows a better result with a lognormal distribution and a greater convergence. It can be assumed that the recording quality has a low noise and the subsurface may be more compact than those of the AT01 point. The AT14 shows a convergence of representative frequency at $4.8 \mathrm{~Hz}$ from the geometric mean. Meanwhile, the frequency from the multipleazimuths method also produces similar values with the frequency range of $4.8-5.0 \mathrm{~Hz}$. Both methods have a low uncertainty meaning that the selected window is optimum along the whole trace.

\section{Conclusion}

We perform a preliminary analysis for two points at AT01 point and AT14 point. The analysis was carried out with the help of the geometric-mean and the multiple azimuths. Both methods noticed that the more compact material are located on the eastern part of the study area with a $\sim 4.8 \mathrm{~Hz}$ representative frequency whilst the soft material rests in the northern part with a $\sim 0.8 \mathrm{~Hz}$ representative frequency. The convergence results of low uncertainty can be found if the trace has a low noise and greater length of recording time. This preliminary study is important to be applied for all point measurements.

\section{References}

1. Pasari, S., Simanjuntak, A. V., Mehta, A., Sharma, Y. Pure and Applied Geophysics, 1-18. (2021).

2. Nurana, I., Simanjuntak, A. V. H., Umar, M., Kuncoro, D. C., Syamsidik, S., \& Asnawi, Y. (2021). Spatial Temporal Condition of Recent
Seismicity In The Northern Part of Sumatra. Elkawnie: Journal of Islamic Science and Technology, 7(1), 131-145.

3. Muksin, U., Bauer, K., Muzli, M., Ryberg, T., Nurdin, I., Masturiyono, M., Weber, M. Journal of Asian Earth Sciences, 171, 20-27. (2019)

4. Muksin, U., Rusydy, I., Erbas, K., \& Ismail, N. (2018, April). Investigation of Aceh Segment and Seulimeum Fault by using seismological data; A preliminary result. In Journal of Physics: conference series (Vol. 1011, No. 1, p. 012031). IOP Publishing.

5. Simanjuntak, A. V., Muksin, U., Setiawan, Y. In IOP Conference Series: Earth and Environmental Science (Vol. 273, No. 1, p. 012021). IOP Publishing. (2019, June).

6. Qadariah, Q., Simanjuntak, A. V., Umar, M. Journal of Aceh Physics Society, 7(3), 127-132. (2018).

7. Rusydy, I., Idris, Y., Muksin, U., Cummins, P., \& Akram, M. N. (2020). Shallow crustal earthquake models, damage, and loss predictions in Banda Aceh, Indonesia. Geoenvironmental Disasters, 7(1), 1-16.Yunita Idris

8. Simanjuntak, A. V., Muksin, U., \& Rahmayani, F. (2018, May). Microtremor survey to investigate seismic vulnerability around the Seulimum Fault, Aceh Besar-Indonesia. In IOP Conference Series: Materials Science and Engineering (Vol. 352, No. 1, p. 012046). IOP Publishing.Andre hvsr

9. Simanjuntak, A. V. H., Asnawi, Y., Umar, M., Rizal, S., \& Syukri, M. (2020). A Microtremor Survey to Identify Seismic Vulnerability Around Banda Aceh Using HVSR Analysis. Elkawnie: Journal of Islamic Science and Technology, 6(2), 342-358.Asrillah

10. Irwandi, I., Muksin, U., \& Simanjuntak, A. V. (2021). Probabilistic seismic hazard map analysis for Aceh Tenggara district and microzonation for Kutacane city. In IOP Conference Series: Earth and Environmental Science (Vol. 630, No. 1, p. 012001). IOP Publishing.

11. Simanjuntak, A. V., Muksin, U., \& Sipayung, R. M. (2018, December). Earthquake relocation using HypoDDMethod to investigate active fault system in Southeast Aceh. In Journal of Physics: Conference Series (Vol. 1116, No. 3, p. 032033). IOP Publishing.

12. Julius, A. M., \& Widana, I. D. K. K. In IOP Conference Series: Earth and Environmental Science (Vol. 708, No. 1, p. 012106). IOP Publishing. (2021, April)

13. Julius, A. M., Pribadi, S., \& Muzli, M. In IOP Conference Series: Earth and Environmental Science (Vol. 132, No. 1, p. 012012). IOP Publishing. (2018, March).

14. Yutaka Nakamura; What Is the Nakamura Method?. Seismological Research Letters 2019;; 90 (4): 1437-1443. doi: https://doi.org/10.1785/0220180376

15. Stanko, D., Markušić, S., Strelec, S., \& Gazdek, M. (2016). Seismic response and vulnerability of historical Trakošćan Castle, Croatia using HVSR method. Environmental Earth Sciences, 75(5), 368. 
16. Tarabusi, G., \& Caputo, R. (2017). The use of HVSR measurements for investigating buried tectonic structures: the Mirandola anticline, Northern Italy, as a case study. International journal of earth sciences, 106(1), 341-353.

17. Bignardi, S. (2017). The uncertainty of estimating the thickness of soft sediments with the HVSR method: A computational point of view on weak lateral variations. Journal of Applied Geophysics, $145,28-38$

18. Cheng, T., Cox, B. R., Vantassel, J. P., \& Manuel, L. (2020). A statistical approach to account for azimuthal variability in single-station HVSR measurements. Geophysical Journal International, 223(2), 1040-1053.

19. Cox, B. R., Cheng, T., Vantassel, J. P., \& Manuel, L. (2020). A statistical representation and frequency-domain window-rejection algorithm for single-station HVSR measurements. Geophysical Journal International, 221(3), 2170-2183.

20. Vantassel, J. P., \& Cox, B. R. (2021). SWinvert: a workflow for performing rigorous 1-D surface wave inversions. Geophysical Journal International, 224(2), 1141-1156.

21. Vantassel, J. P., \& Cox, B. R. (2021). A procedure for developing uncertainty-consistent Vs profiles from inversion of surface wave dispersion data. Soil Dynamics and Earthquake Engineering, 145, 106622.

22. Asnawi, Y.; Simanjuntak, A.; Muksin, U.; Okubo, M.; Putri, S.I.; Rizal, S.; Syukri, M., (2022). Soil classification in a seismically active environment based on shear wave velocity and HVSR data. Global J. Environ. Sci. Manage., 8(3): 1-18. 